\title{
Effects of canopy coverage on the immature stages of the Clouded Apollo butterfly [Parnassius mnemosyne (L.)] with observations on larval behaviour
}

\author{
Panu Välimäki \& Juhani Itämies
}

Välimäki, P. \& Itämies, J. 2005: Effects of canopy coverage on the immature stages of the Clouded Apollo butterfly [Parnassius mnemosyne(L.)] with observations on larval behaviour. - Entomol. Fennica 16: 117-123.

The immature stages of the Clouded Apollo (Parnassius mnemosyne) are assumed to be thermophilic due to the possible time limitations and variable weather conditions during their development. Thus, the degree of canopy coverage may affect habitat use by the species. We explored the spatial distribution of larvae and the development time of pupae under variable canopy coverage conditions. Larvae were most abundant in the areas exposed to direct sunlight, although the last instar larvae are mobile. Larvae also basked under litter between their foraging periods, probably to enhance digestion and the food intake rate. Moreover, pupal development was retarded by increasing canopy coverage. Prolonged pupal development and larval avoidance of Corydalis growths under tree canopies indicate that the species suffers from overgrowing and consequently increasing canopy coverage.

P. Välimäki \& J. Itämies, University of Oulu, Department of Zoology, P. O. Box 3000,FI-90014 University of Oulu, Finland; E-mail: panu.valimaki@oulu.fi, juhani.itamies@oulu.fi

Received 28 May 2003, accepted 13 February 2004

\section{Introduction}

The Clouded Apollo butterfly [Parnassius mnemosyne (L.)] is considered a threatened species in northern and central Europe (Heath 1981, Aagaard et al. 1997, Konvicka \& Kuras 1999, Rassi et al. 2001). Its distribution has declined remarkably in Finland since the early $20^{\text {th }}$ century (Mikkola 1979, Väisänen \& Somerma 1985). This trend has been related to changes in agricultural practices and, consequently, to decreasing area and deteriorating quality of formerly habitable meadows (Väisänen \& Somerma 1985). The Clouded Apollo was protected in Finland by the nature conservation act in 1976 [Maa- ja metsätalousministeriö (1976), see also Mikkola \& Häkkinen (1977)]. However, effective conservation is not possible if the biology of the species is not adequately known.

Adults prefer to breed and forage on open meadows with abundant larval food plant and nectar sources (Luoto et al. 2001). Larvae are mostly found at the sunny margins of humid deciduous forests (Meglécz et al. 1999). Although the larval food plants vary spatially, the Clouded Apollo is locally monophagous. In Finland, larvae feed only on Corydalis solida (Somerma 1997), but in Norway and Hungary, larvae feed 
on Corydalis intermedia (Aagaard \& Hanssen 1989) and Corydalis cava (Meglécz et al. 1999), respectively.

Corydalis solida grows in at least two different habitats in SW Finland. It is abundant in deciduous forests dominated by Alnus spp., Prunus padus or Betula spp. along the seashore. On the other hand, it also grows on open or semi-open mesic meadows, pastures and abandoned fields (Välimäki et al. 2000, Luoto et al. 2001). A locally monophagous species, the Clouded Apollo is obligatorily dependent on C. solida that flowers very early in the spring. Larvae must develop fast because their host is available for only a few weeks before senescence. However, the weather is usually quite unpredictable and cold in Finland at the time of the larval development, which retards larval growth.

In addition, Corydalis species contain a wide range of secondary metabolites, such as alkaloids (Naruto \& Kaneko 1972, Naruto et al. 1972, Siegler 1998). These plant compounds may act as a defence mechanism against herbivores (Fraenkel 1959), and they may result in a plant becoming inadequate as food (Scoble 1995). The effects of secondary metabolites on specialist herbivores are, nevertheless, not necessarily detrimental (Macel et al. 2002). This indicates that the evolution of defensive compounds may rather be driven by generalist herbivores, which also suffer most, as suggested by Hägele \& Rowell-Rahier (2000). Although Corydalis is available for larvae only ephemerally, it may be a very profitable host, because the detrimental secondary substances may create an almost competition-free space for a species adapted to the chemical composition of the plant.

The aim of this paper is twofold. (a) Firstly, we study the effects of canopy coverage on the spatial distribution of larvae and pupal development. (b) Secondly, we present observations on larval behaviour in the natural environment. Larval development is not only affected by food quality, but also by temperature and the interactions of these two factors (Stamp \& Yang 1996). Thus, overgrowing by trees and bushes and the consequently decreasing daytime temperature in the ground layer usually retard larval growth. If the time available for larval development is a crucial factor, larvae are expected to be thermophilic and to be found only on the open and sunny parts of Corydalis growths. If decreasing temperature delays pupal development as well, increasing canopy coverage may decrease the effective population size. Thus, the Clouded Apollo may suffer from overgrowing.

\section{Material and methods}

\subsection{Study area}

The study area is located in SW Finland (61 ${ }^{\circ} 13^{\prime}$ $\left.\mathrm{N}, 21^{\circ} 31^{\prime} \mathrm{E}\right)$. The landscape is typical of Finnish agricultural areas - mostly dense Norway spruce (Picea abies) forest or very dry Scots pine (Pinus sylvestris) heath forest fragmented by small meadows and cultivated fields. In spring 1999, we surveyed the whole study area $\left(2.7 \mathrm{~km}^{2}\right)$ in detail to map the distribution and location of $C$. solida growths (Välimäki et al. 2000).

\subsection{Distribution of larvae}

The effect of canopy coverage on the spatial distribution of larvae was studied in 2000 (18-19 May) in a large (ca. 6,700 $\mathrm{m}^{2}$ ) continuous Corydalis growth with canopy coverage by trees and bushes [mostly birches (Betula spp.) and hagberry (Prunus padus)] varying from $0 \%$ to $100 \%$. At first, we divided the study patch into $10 \mathrm{~m} \times 10$ $\mathrm{m}$ squares that were classified according to the canopy cover on a scale of $1-3[1=<10 \%$ (open), $2=20-59 \%$ (semi-open), $3=>60 \%$ (overgrown)]. Birch leaves had reached approximately three-fourth of their final size, and hagberry leaves were almost fully grown at that time. Most of the Clouded Apollo larvae collected for rearing were in their final instar and pupated within the next week.

To explore the distribution of larvae, we calculated the relative number of eaten shoots from 16 randomly-chosen squares in each coverage class. Biting marks were recorded as 1 (detectable bites) or 0 (no detectable bites). Marks were recorded from the 20 shoots growing closest to the centre point of each square. We assumed that the relative number of eaten shoots would indicate the relative abundance of larvae in each square 
with reasonable accuracy. Biting marks were counted during two successive days to ensure that the ratio of eaten to intact shoots would not change as the counting proceeded.

The larval biting marks of the Clouded Apollo are species-specific and therefore easily distinguishable from other causes of defoliation, such as deer bites. To exclude the possibility of other insect herbivores, we examined carefully the vicinity of hundreds of eaten Corydalis shoots, but did not find any larvae of other insect species. The only other lepidopteran species found feeding on C. solida was a polyphagous tortricoid moth, Cnephasia asseclana (D. \& S.). The larvae of this moth, unlike those of the Clouded Apollo, always spin a few leaflets together. Although we cannot be absolutely sure that all of the counted biting marks had been caused by larvae of the Clouded Apollo, it seems unlikely that any other herbivore could have been responsible for the defoliation of C. solida in our study area.

Temperature measurements in the three canopy-coverage classes were carried out on the $14^{\text {th }}$ of May in 2002. Temperature in the ground layer was measured at 12 randomly chosen sites (4 in each class). Measurements were repeated at intervals of 15 minutes from 10:00 AM to 12:10 PM. Corresponding ambient temperatures were recorded at the height of $1.5 \mathrm{~m}$ above each measurement site.

\subsection{Development time}

The effect of canopy shading on pupal development time was studied in 2002 by rearing individuals under different kinds of canopy coverage. Larvae $(n=17)$ were collected on the $14^{\text {th }}$ of May 2002 from the study area and reared into pupae on fresh C. solida. After pupation, the offspring were randomly divided into two treatments. Group 1 was placed on an open field exposed to direct sunshine. Group 2 was placed under trees with 50\% canopy coverage to simulate an overgrown meadow. During the study, temperature in the ground layer was recorded continuously with thermometers. From thermometer data, we calculated the cumulative heat summation required for the development of pupae into adults. The results are reported as means \pm 1 S.E.

\subsection{Larval behaviour}

Observations on larval behaviour were made in 2000 and 2002 in the natural environment. In 2000, we made only subjective notes while searching for larvae for the rearing experiment $(n$ =13). The main aim was to explore the parasitoid pressure towards the Clouded Apollo in our study area. On the $14^{\text {th }}$ of May 2002, we studied larval behaviour in a more detailed way by observing the feeding behaviour of the last instar larvae $(n=$ 10) on a warm and sunny day. We recorded the time spent by larvae in foraging, after which we continued to follow larval behaviour for another 30 minutes. To explain larval behaviour, we measured the temperature both above and under the surface of the litter layer where the larvae were hiding. The accuracy of these temperature measurements was 0.1 degrees of centigrade.

\subsection{Data analysis}

Variation in the relative number of eaten shoots among canopy coverage classes was compared with non-parametric Kruskal-Wallis one-way ANOVA and non-parametric Tukey's post hoc test. The effect of canopy coverage on pupal development time was explored with parametric $t$ test. Temperature comparisons among canopy coverage classes were made with ANOVA and LSD post hoc test. The differences in temperature on and under the surface of the litter layer were tested with paired samples $t$-test. All statistical analyses, excluding Tukey's post hoc test, were conducted with the SPSS for Windows 10.0 statistical software.

\section{Results}

\subsection{Distribution of larvae}

The relative number of eaten shoots varied among canopy coverage classes $\left(\chi^{2}=9.594, d f=\right.$ $2, p=0.008$ ) (Fig 1). In the squares classified as open, $11 \%$ of the shoots were defoliated to some extent by larvae, while only $7 \%$ and $3 \%$ of the shoots in the semi-open and overgrown squares were eaten, respectively. This variation was non- 

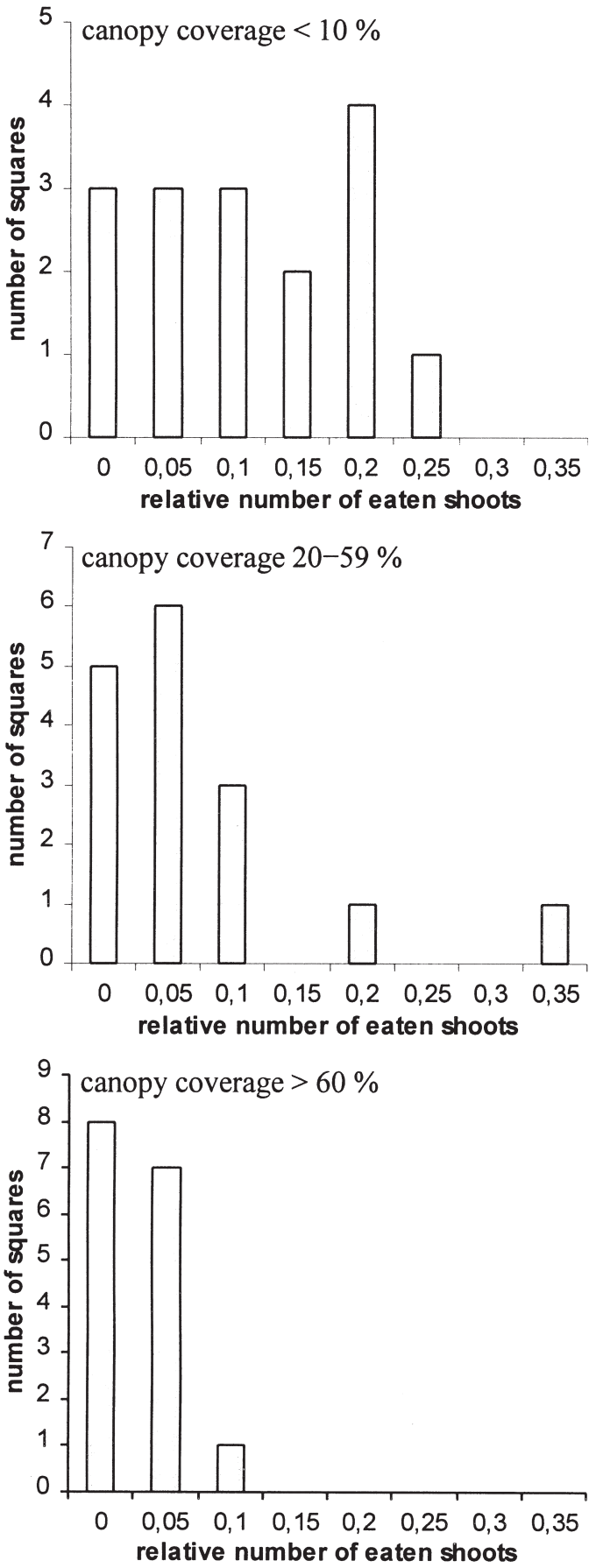

Fig. 1. Distribution of the relative numbers of eaten Corydalis solida shoots under variable canopy coverage.

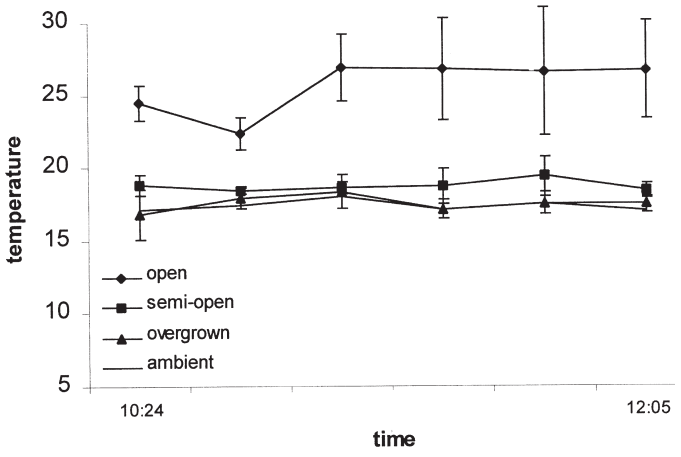

Fig. 2. Average temperature $\left({ }^{\circ} \mathrm{C}\right)$ in the ground layer at open, semi-open and overgrown sites, and corresponding ambient temperature $1.5 \mathrm{~m}$ above the ground before noon on $14^{\text {th }}$ of May 2002.

significant between the open and semi-open squares $(q=2.189, p>0.05)$, but significant between the open and overgrown squares $(q=$ 4.214, $p<0.05$ ).

Average temperature in the ground layer varied among the canopy coverage classes $\left(F_{3,12}=\right.$ $65.699, p<0.001)$ and was evidently higher at open than semi-open and overgrown sites (LSD post hoc test: $p<0.001$ ) (Fig. 2). Although the average temperature in the ground layer in semiopen sites was consistently higher than the ambient temperature, the difference was non-significant (LSD post hoc test: $p=0.06)$.

\subsection{Development time of pupae}

The average required heat summation from pupation to the emergence of adults was $300^{\circ} \mathrm{C}$ $( \pm 85.6)$ in treatment 2 (shade) and $286^{\circ} \mathrm{C}( \pm 42.0)$ in treatment 1 (sunshine). There was no variation in this respect between the treatments $(t=0.394$, $d f=11, p=0.701)$. However, it took longer to reach the required heat summation under trees than on open field (Fig 3). Consequently, the pupal stage was significantly longer in shade than in sunshine ( $t=3.784, d f=11, p=0.003)$ (Fig. 4). Butterflies hatched after an average of $16.5( \pm 2.6)$ and $26.8( \pm 7.2)$ days after pupation on open field exposed to direct sunshine and under trees, respectively. In addition, pupal survival seemed to be less good in the shady compared to the sunny environment (62\% vs.100\%). 


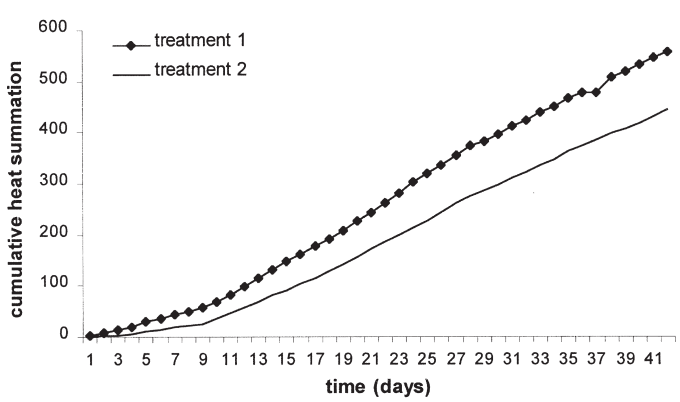

Fig. 3. Cumulative heat summation at a site exposed to direct sunshine (treatment 1 ) and a site with $50 \%$ canopy coverage (treatment 2) 16.V.-27.VI. 2002.

\subsection{Larval behaviour}

Larvae started their feeding period at about 11:00 $\mathrm{AM}$, when ambient temperature at $1.5 \mathrm{~m}$ height was $18^{\circ} \mathrm{C}$. At the same time, the average temperature in the ground layer at open sites was $26^{\circ} \mathrm{C}$. Larvae in that particular patch started feeding quite simultaneuosly, indicating that there might be a threshold temperature that needs to be exceeded for efficient foraging. Larvae foraged for an average of 10 minutes $(9.7 \pm 2.07)$, after which they dropped to the ground. When done with their feeding, they crawled rapidly $10-30 \mathrm{~cm}$ away from the eaten shoot. They usually basked in direct sunshine for a few minutes and then hid under detritus (usually old brownish leaves of deciduous trees) just beneath the surface of the litter, where moulting and pupation also take place. The temperature of the hiding places was consistently higher $(10 \%$ on average) than the ambient temperature just above the litter layer $(t=-4.164, d f=$ $10, p=0.002$ ). Larvae always hid for more than 30 minutes between successive foraging sessions. The next foraging hardly ever takes place on the same plant as the previous session, but rather on a randomly chosen shoot near the hiding place. Feeding went on until the late afternoon in sunny weather. Early in the morning and in cloudy weather, larvae were found to remain hiding among litter.

Larvae fed on leaves, flowers and fresh cores of $C$. solida, but seemed to avoid seeds. Usually, the whole leaflet and the attached petiole were eaten, which made the biting marks less detectable.

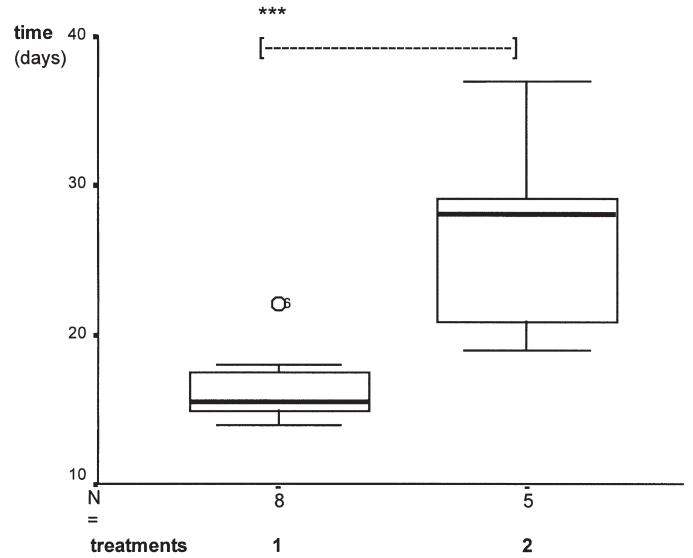

Fig. 4. Average pupal development time of the Clouded Apollo (Parnassius mnemosyne) at a site exposed to direct sunshine (treatment 1) and a site with $50 \%$ canopy coverage (treatment 2 ). Asterisks show statistical significance between treatments $\left({ }^{* *}=p\right.$ $<0.01)$.

\section{Discussion}

Canopy coverage affects significantly the spatial distribution of Clouded Apollo larvae within a continuous Corydalis growth, with most larvae inhabiting the open parts of the meadow, where the average temperature in the ground layer is higher than in the shady parts. The larval distribution and behaviour as well as the retarded pupal development due to increasing shading by leaves indicate that the species is thermophilic and therefore suffers from overgrowing of its habitats. As a consequence, Corydalis shoots growing in dense deciduous forest are not of great value for the Clouded Apollo.

The distribution of biting marks suggested that larvae are most abundant in areas exposed to direct sunlight. There were practically no signs of larvae in the most overgrown parts of the study patch, although some mated females were observed there in 1999 and 2000. The pattern may arise from offspring preference or performance, but also from the oviposition behaviour of females. Females may determine the host use by the species if larvae are relatively immobile and consequently restricted to the resources and place chosen by the ovipositing female (Singer et al. 1991, Janz \& Nylin 1997). Nevertheless, the last instar larvae of the Clouded Apollo moved re- 
peatedly among $C$. solida shoots, suggesting that larvae may be capable of moving, even quite freely, within their habitat. However, the food plants growing under trees and bushes were still mostly intact. This indicates that larvae may avoid shady Corydalis growths. Even if females did not lay any eggs on Corydalis growths in overgrown areas, mobile larvae could be expected to colonize this resource before leaf burst, when overgrown areas are practically as sunny as open ones. However, the early larval instars may not be equally mobile than the last two. Habitat use by Clouded Apollo larvae may therefore be initially determined by the ovipositing female, but because of the increasing larval mobility, the observed distribution may later actually represent larval habitat preference as well.

Whatever the reason for this larval distribution, it is evident that open areas are essential for the species. Due to the increasing canopy coverage, cumulative heat summation accumulates more slowly in overgrown than in open habitats, which explains the observed variation in pupal development times between the two treatments. Our results suggest that a 50\% increase in canopy coverage does not only increase the pupal development time 1.5-fold, but may also decrease survival by over $30 \%$. The prolonged pupal development per se might not be an overwhelming problem for the species because the larval host plant has already wilted before females begin to lay eggs. However, the variable pupal development time due to unequally increasing canopy coverage decreases effective population size by decreasing the number of contemporarily flying individuals, which may also affect population dynamics by decreasing the mating success of individuals [see Kuussaari et al. (1998) for the effects of density-dependent mating success on population survival]. Moreover, due to the larval avoidance of shady habitats, an increasing proportion of food resources becomes useless during late larval development, when the food intake rate is usually highest. Therefore, overgrowing might also increase larval mortality, at least if Corydalis is scarce.

The early senescence of the host is probably the most evident problem faced by larvae. Fast development requires an effective foraging strat- egy that maximizes the food intake rate. In that sense, the short foraging sessions and the relatively long hiding phases seem quite peculiar. Several reasons may explain this larval behaviour. Larvae may hide in order to avoid (a) predators and (b) parasitoid attacks, or (c) they may accelerate their digestion and increase their food intake efficiency by basking under litter.

In the first two cases, there are apparent costs in terms of increased mortality related to feeding visible to enemies. However, many papilionid larvae, including the Clouded Apollo, are distasteful and aposematically patterned (Scoble 1995). Aposematism usually reduces the risk of predation or the detrimental effects of predator attacks on larval survival significantly (Wiklund \& Sillén-Tullberg 1985, Roper \& Redston 1987, Tullrot \& Sundberg 1991). The secretory products of the specialized defensive organs of papilionid butterflies, the osmeteria, may affect not only predators, but also parasitoids (Scoble 1995). In accordance, out of 30 reared larvae, none were parasitized, indicating low parasitoid pressure towards the Clouded Apollo butterfly in our study area. Thus, predation pressure and parasitoid attacks have probably only a minor effect on larval behaviour.

The extent to which larval behaviour was affected by avoidance of natural enemies nevertheless remains without final elucidation. Generally, however, the food intake rate and the growth rate of the immature stages of ectothermic animals usually increase along with rising temperature (Heinrich 1973). Because temperature was consistently higher just beneath than above the surface of the litter layer, the need for increased food digestion seems the most plausible explanation for the larval behaviour observed here. The difference in temperature may be even more pronounced, especially in coastal areas, where wind cools ambient temperature effectively in spring. In addition to the possibility of more effective digestion, larvae may also benefit from a reduced risk of desiccation by hiding among the litter with high relative humidity. Thus, behaviour that may at first sight seem maladaptive could actually turn out to manifest adaptation to the short season of the host and the unstable thermal conditions during larval development. 
Acknowledgements. We thank Olavi Helminen for help in the field and Marko Mutanen for valuable comments on the manuscript. The town of Rauma, Teollisuuden Voima $\mathrm{OY}$ and Southwest Finland Regional Environment Centre financially supported this study. The permission to collect and rear larvae was granted by Southwest Finland Regional Environment Centre [permission no. 0299LO386254, 0200LO221-254 (Project B 2017)].

\section{References}

Aagaard, K. \& Hanssen, O. 1989: Population studies of Parnassius mnemosyne (Lepidoptera) in Sunndalen, Norway. — In: Paulicek-van Beek, T., Ovaa, A. H., van der Made, J. (eds.), Future of butterflies in Europe: strategies for survival: 160-166. Agricultural University, Wageningen.

Aagaard, K., Hindar, K., Hanssen, 0., Balstad, T. \& Fjellstad, W. 1997: Population structure and genetic diversity of Norwegian populations of Parnassius mnemosyne and Parnassius apollo (Lepidoptera). NINA Oppdragsmelding 462: 1-20.

Fraenkel, G. S. 1959: The raison d'être of secondary plant substances. - Science 129: 1466-1470.

Heath, J. 1981: Threatened Rhopalocera (butterflies) in Europe. - Council of Europe, Environmental Series 23: $1-157$.

Heinrich, B. 1973: Mechanisms of insects thermoregulation. - In: Weiser, W. (ed.), Effects of Temperature on Ectothermic Organism; Ecological Implications and Mechanisms of Compensation: 139-150. Springer-Verlag, Berlin.

Hägele, B. F. \& Rowell-Rahier, M. 2000: Choice, performance and heritability of performance of specialist and generalist insect herbivores towards cacalol and seneciphylline, two allelochemicals of Adenostyles alpina (Asteraceae). - Journal of Evolutionary Biology 13: 131-142.

Janz, N. \& Nylin, S. 1997: The role of female search behaviour in determining host plant range in plant feeding insects: a test of the information processing hypothesis. - Proceedings of the Royal Society of London B 264: 701-707.

Konvicka, M. \& Kuras, T. 1999: Population structure, behaviour and selection of oviposition sites of an endangered butterfly, Parnassius mnemosyne, in Litovelske Pomoravi, Czech Republic. - Journal of Insect Conservation 3: 211-223.

Kuussaari, M., Saccheri, I., Camara, M. \& Hanski, I. 1998: Allee effect and population dynamics in the Glanville fritillary butterfly. — Oikos 82: 384-392.

Luoto, M., Kuussaari, M., Rita, H., Salminen, J. \& von Bonsdorff, T. 2001: Determinants of distribution and abundance in the Clouded apollo butterfly: a landscape ecological approach. - Ecography 24: 601617.

Macel, M., Klinkhamer, P. G. L., Vrieling, K. \& van der
Meijden, E. 2002: Diversity of pyrrolizidine alkaloids in Senecio species does not affect the specialist herbivore Tyria jacobaeae. - Oecologia 133: 541-550.

Meglécz, E., Néve, G., Pecsenye, K. \& Varga, Z. 1999: Genetic variations in space and in time in Parnassius mnemosyne (L.) (Lepidoptera) populations in northeast Hungary: implications for conservation. - Biological Conservation 89: 251-259.

Mikkola, K. 1979: Vanishing and declining species of Finnish Lepidoptera. - Notulae Entomologicae 59: $1-9$.

Mikkola, K. \& Häkkinen S.-L. 1977: Minne ovat apolloperhoset hävinneet? - Suomen Luonto 36: 35-38. [In Finnish.]

Maa- ja metsätalousministeriö [Ministry of Agriculture and Forestry] 1976: Asetus (N:o 440) eräiden harvinaisten eläinten rauhoittamisesta. — Baptria 1: 43. [In Finnish.]

Naruto, S. \& Kaneko, H. 1972: Constituents of Corydalis stewartii. - Phytochemistry 11: 2644.

Naruto, S., Namba, K. \& Kaneko, H. 1972: Alkaloids from several tuberous Corydalis species. - Phytochemistry 11: 2642-2643.

Rassi, P., Alanen, A., Kanerva, T. \& Mannerkoski, I. (eds.) 2001: Suomen lajien uhanalaisuus 2000. - Ympäristöministeriö \& Suomen ympäristökeskus, Helsinki [In Finnish with English summary].

Roper, T. J. \& Redston, S. 1987: Conspicuousness of distasteful prey affects the strength and durability of onetrial avoidance learning. - Animal Behaviour 35: 739-747.

Scoble. M. J. 1995: The Lepidoptera: form, function, and diversity. - Oxford University Press, Oxford. 404 pp.

Siegler, D. S. 1998: Plant Secondary Metabolism. Kluwer Academic Publishers, London. 759 pp.

Singer, M. C., Ng, D. \& Moore, A. 1991: Genetic variation in oviposition preference between butterfly populations. - Journal of Insect Behaviour 4: 531-535.

Somerma, P. 1997: Threatened Lepidoptera in Finland. Environmental Guide 22: 1-336.

Stamp, N. E. \& Yang, Y. 1996: Response of insect herbivores to multiple allelochemicals under different thermal regimes. - Ecology 77: 1088-1102.

Tullrot, A. \& Sundberg, P. 1991: The conspicuous nudibranch Polycera quadrilineata: a aposematic coloration and individual selection. - Animal Behaviour 4: 175-176.

Väisänen, R. \& Somerma, P. 1985: The status of Parnassius mnemosyne (Lepidoptera, Papilionidae) in Finland. - Notulae Entomologicae 65: 109-118.

Välimäki, P., Itämies, J. \& Helminen, O. 2000: [The occurrence of the Clouded apollo (Parnassius mnemosyne) around Rauma, SW Finland in 1999.] — Babtria 25: 61-69. [In Finnish with English abstract].

Wiklund, C. \& Sillén-Tullberg, B. 1985: Why distasteful butterflies have aposematic larvae and adults, but cryptic pupae: evidence from predation experiments on the monarch and the European swallowtail. - Evolution 39: 1155-1158. 